\title{
An Optimal Method for Developing Global Supply Chain Management System
}

\author{
Hao-Chun Lu' ${ }^{1}$ and Yao-Huei Huang ${ }^{2}$ \\ ${ }^{1}$ Department of Information Management, College of Management, Fu Jen Catholic University, No.510 Jhongjheng Road, \\ Sinjhuang City, Taipei County 242, Taiwan \\ ${ }^{2}$ Institute of Information Management, National Chiao Tung University, Management Building 2, 1001 Ta-Hsueh Road, \\ Hsinchu 300, Taiwan
}

Correspondence should be addressed to Yao-Huei Huang; yaohuei.huang@gmail.com

Received 31 January 2013; Accepted 2 June 2013

Academic Editor: Irem Ozkarahan

Copyright (C) 2013 H.-C. Lu and Y.-H. Huang. This is an open access article distributed under the Creative Commons Attribution License, which permits unrestricted use, distribution, and reproduction in any medium, provided the original work is properly cited.

Owing to the transparency in supply chains, enhancing competitiveness of industries becomes a vital factor. Therefore, many developing countries look for a possible method to save costs. In this point of view, this study deals with the complicated liberalization policies in the global supply chain management system and proposes a mathematical model via the flow-control constraints, which are utilized to cope with the bonded warehouses for obtaining maximal profits. Numerical experiments illustrate that the proposed model can be effectively solved to obtain the optimal profits in the global supply chain environment.

\section{Introduction}

Traditionally, supply chain management (SCM) mainly offers different ways to reduce the production and transportation costs such that either the total expenditures in a supply chain can be minimized $[1,2]$ or the profits can be maximized $[3,4]$ to enhance the industrial competitiveness. These concepts above have been formed as SCM mathematical models in the last few decades such as supplier's pricing policy in a justin-time environment [5], pricing strategy for deteriorating items using quantity discount when customer demand is sensitive [6], and an optimization approach for supply chain management models with quantity discount policy [7].

On the other hand, a part of studies is focused on demand forecasting [8-11] to decrease the impact of the bullwhip effect $[12,13]$. Additionally, some studies utilize the neural network method and regression analysis to improve the accuracy for forecasting customer demand [14-16], and furthermore, these connection weights in neural networks are assigned weighting based on fuzzy analytic hierarchy process methods without any tunings $[14,17]$. By the previous mentions, we cannot guarantee that the solution are optimal.
Based on the reason, this study proposes a deterministic method, an approximate method for linearizing nonlinear time series analysis model, to forecast customer demand in Section 3.2.

Many researchers have suggested that information sharing is a key influence on SCM environments [11, 18] and that it impacts the SCM performance in terms of both total costs and service levels $[11,19,20]$. However, the development of a global SCM model must share information as much as possible. We then suppose that the information in our experimental tests is shared to simplify the SCM situations [21-23].

In order to enhance the competitiveness of industries, a liberalization policy discussed in recent years becomes an important factor. Many developing countries have implemented a liberalization policy with bonded warehouses in the global supply chain environments. The liberalization policy with bonded warehouses in the different countries around the world, makes the goods be stored in the bonded warehouse, the liability of exporter is temporally cancelled, and the importer and warehouse proprietor incur liability. A 


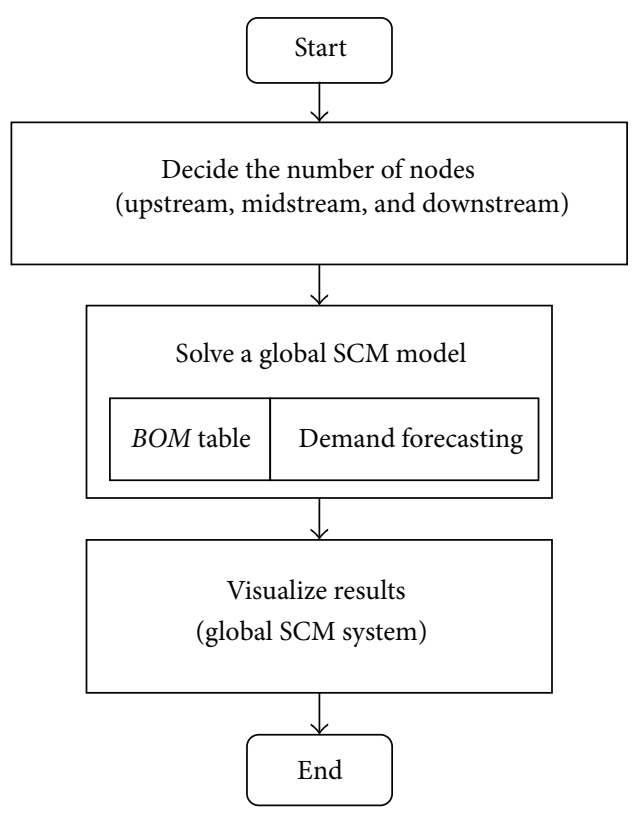

FIGURE 1: A flow chart of the proposed procedure.

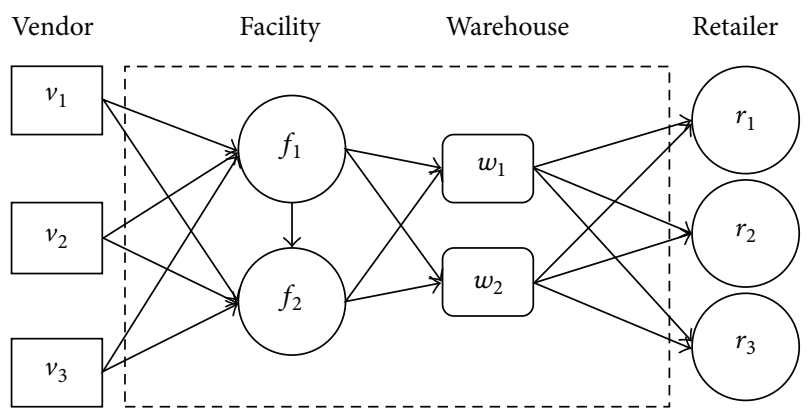

FIGURE 2: Schema of a global SCM.

bonded warehouse is one building or another secured area, where dutiable goods may be stored or processed without payment of duty. It may be managed by the state or by a private enterprise. The liberalization policy with bonded warehouses not only enhances the industries competitiveness but also saves inventory, production and transportation costs. Of course, the objective is to find more bonded warehouses, and more costs can be saved. In this study, the policy has proved the advantage for the exporter obtaining more profit in our numerical examples [24-28].

A global SCM is seen as a network that includes upstream, midstream and downstream sectors linkage, where we consider vendors as upstream, facilities and warehouses as midstream, and retailers (or customers) as downstream. The liberalization policy focuses on bonded warehouses of midstream in different countries around the world is not considered in the current SCM model $[7,29]$. In this study, we then propose a global SCM model to be suitable for the international liberalization policy. The objective is to maximize the profits associated with inventory, production, transpiration, and distribution in the period of times. The global SCM model is formed as a linear mixed-integer program and solved by commerce software (i.e., [30]). Then, a flow chart for the proposed procedure is depicted in Figure 1.

This paper is organized as follows. Section 2 defines the notations in global SCM and forms a basic model of global SCM. Section 3 describes a procedure of global SCM. Section 4 shows the system architecture of a global SCM. Finally, numerical examples demonstrate that the proposed global SCM method can enhance profit ratio in Section 5.

\section{A Global SCM Model}

There are four stages in the global SCM environment discussed: the vendor, facility, warehouse, and retailer. Each stage may be located in different nations around the world. The general structure of a global supply chain network has been displayed in Figure 2. For simplifying presentation, both income and cost statements occur in the dashed rectangle as follows.

(i) Income statement

(a) sales of goods in warehouse,

(b) transfer price of goods in facility.

(ii) Cost statement

(a) procurement cost from vendor,

(b) transportation cost (i.e., vendor to facility, facility to warehouse, and warehouse, to retailer),

(c) inventory cost (i.e., warehouse).

Notations are described in Section 2.1, and a basic model of global SCM is formulated in Section 2.2.

\subsection{Notations. There are seven entity sets}

$N$ : The set of nations $n$

$V$ : The set of vendors $v$

$F$ : The set of facilities $f$

$W$ : The set of warehouses $w$

$R$ : The set of retailers $r$

$T$ : The set of times $t$

$P$ : The set of parts (or goods) $p$

for presenting each entity associated with notations as shown above.

All parameters are composite style, which are composed of uppercase English strings and suffixes with one or more lowercase alphabet characters, and each suffix single lowercase alphabet character presents the element of relative entity sets. These parameters are

PRICE $E_{w p}$ : The sales price of part $p$ in warehouse $w$. $T_{\text {TPRICE }}$ : The transfer price of part $p$ in facility $f$. PPRICE ${ }_{v p}$ : The procurement cost of part $p$ from vendor $v$. 
$\operatorname{MCOST}_{f p}$ : The production cost of part $p$ in facility $f$. $\operatorname{TCOST}_{v f}$ : The basis of transportation costs from vendor $v$ to facility $f$.

$\operatorname{TCOST}_{f f^{\prime}}$ : The basis of transportation costs from facility $f$ to facility $f^{\prime}$.

TCOST $_{f w}$ : The basis of transportation costs from facility $f$ to warehouse $w$.

$\mathrm{TCOST}_{w r}$ : The basis of transportation costs from warehouse $w$ to retailer $r$.

$\operatorname{ICOST}_{f}$ : The basis of inventory costs in facility $f$.

$I \operatorname{COST}_{w}$ : The basis of inventory costs in warehouse $w$.

$T_{v f}$ : The transportation time from vendor $v$ to facility $f$.

$T_{f f^{\prime}}$ : The transportation time from facility $f$ to facility $f^{\prime}$.

$T_{f w}$ : The transportation time from facility $f$ to warehouse $w$.

$T_{w r}$ : The transportation time from warehouse $w$ to retailer $r$.

Tbom $_{f p}$ : The production time of part $p$ in facility $f$.

$B O M_{p^{\prime} p}$ : The amount for part $p$ reproducing as part $p^{\prime}$.

$P T_{p}$ : The weighting of transportation costs for part $p$.

$P I_{p}$ : The weighting of inventory costs for part $p$.

$D_{t r p}$ : The required quantities of part $p$ for retailer $r$ at time $t$.

$T A X_{n}$ : The tax in nation $n$.

DUTY ${ }_{n p}$ : The import tax of part $p$ in nation $n$.

$L O C_{n v}$ : The vendor $v$ in nation $n$.

$L O C_{n f}$ : The facility $f$ in nation $n$.

$L O C_{n w}$ : The warehouse $w$ in nation $n$.

$L O C_{n r}$ : The retailer $r$ in nation $n$.

$M_{-} U_{f p}$ : The supplied upper level of part $p$ in the facility $f$.

$R_{-} U_{v f p}$ : The supplied upper level of part $p$ from vendor $v$ to facility $f$.

$R_{\_} U_{f f^{\prime} p}$ : The supplied upper level of part $p$ from facility $f$ to facility $f^{\prime}$.

$R_{-} U_{f w p}$ : The supplied upper level of part $p$ from facility $f$ to warehouse $w$.

$R_{-} U_{\text {wrp }}$ : The supplied upper level of part $p$ from warehouse $w$ to retailer $r$.

$I_{-} U_{f p}$ : The inventoried upper level of part $p$ in facility $f$.

$I_{-} U_{w p}$ : The inventoried upper level of part $p$ in warehouse $w$.
All decision variables in global SCM are also compositestyle with lowercase suffix alphabet characters. The details of decision variables (integer variables) are described below:

$R_{t v f p}$ : The amount of part $p$ transported from vendor $v$ to facility $f$ at time $t$

$M_{t f p}$ : The amount of part $p$ produced in facility $f$ at time $t$

$R_{t f f^{\prime} p}$ : The amount of part $p$ transported from facility $f$ to facility $f^{\prime}$ at time $t$

$R_{t f w p}$ : The amount of part $p$ transported from facility $f$ to warehouse $w$ at time $t$

$R_{t w r p}$ : The amount of part $p$ transported from warehouse $w$ to retailer $r$ at time $t$

$I_{t f p}$ : The inventory of part $p$ in facility $f$ at time $t$

$I_{t w p}$ : The inventory of part $p$ in warehouse $w$ at time $t$

$R B_{t v f p}$ : The amount of bonded part $p$ transported from vendor $v$ to facility $f$ at time $t$

$M B_{t f p}$ : The amount of bonded part $p$ produced in facility $f$ at time $t$

$R B_{t f f^{\prime} p}$ : The amount of bonded part $p$ transported from facility $f$ to facility $f^{\prime}$ at time $t$

$R B_{t f w p}$ : The amount of bonded part $p$ transported from facility $f$ to warehouse $w$ at time $t$

$I B_{t f p}$ : The inventory of bonded part $p$ in facility $f$ at time $t$.

2.2. A Proposed Model. We separately use $i b t_{t n}^{+}$, $i b t_{t n}^{-}$, and $T A X_{n}$ as the symbols of sales profits, losses, and taxes in each nation at different times. The objective of the proposed model is to maximize the sales profits associated with inventory, production, transpiration, and distribution in each nation at a period of times. The linear global SCM model is formulated as follows.

\section{A Global SCM Model}

Maximize $\sum_{t \in T, n \in N}\left(\left(1-T A X_{n}\right) i b t_{t n}^{+}-i b t_{t n}^{-}\right)$

subject to

$$
\begin{aligned}
& i b t_{t n}^{+}-i b t_{t n}^{-} \\
&=\sum_{p}\left(\sum _ { w \in W , r \in R , p \in P } \left(R_{t w r p} *\right.\right. \\
&\left.\left(P R I C E_{w p}-P T_{p} * T C O S T_{w r}\right)\right)
\end{aligned}
$$




$$
\begin{aligned}
& -\sum_{f \in F, w \in W, p \in P}\left(R_{t f w p}\right. \\
& \text { *(TPRICE } \left.\left.E_{f p}+P T_{p} * \operatorname{TCOST}_{f w}\right)\right) \\
& -\sum_{f \in F, w \in W, p \in P}\left(\left(R_{t f w p}-R B_{t f w p}\right)\right. \\
& \text { * TPRICE } \left.E_{f p} * D U T Y_{n p}\right) \\
& -\sum_{w \in W, p \in P}\left(I_{t w p} * P I_{p} * I C O S T_{w}\right) \\
& -\sum_{w \in W}\left(\operatorname{FCOST}_{w}\right) \\
& +\sum_{f \in F, w \in W, p \in P}\left(R_{t f w p} * T P R I C E_{f p}\right) \\
& +\sum_{f^{\prime}, f \in F, f^{\prime} \neq f, p \in P}\left(R_{t f f^{\prime} p} * \text { TPRICE }_{f p}\right) \\
& -\sum_{f^{\prime}, f \in F, f^{\prime} \neq f, p \in P}\left(R _ { t f ^ { \prime } f p } * \left(T P R I C E_{f^{\prime} p}\right.\right. \\
& \left.\left.+P T_{p} * \operatorname{TCOST}_{f^{\prime} f}\right)\right) \\
& -\sum_{f^{\prime}, f \in F, f^{\prime} \neq f, p \in P}\left(\left(R_{t f^{\prime} f p}-R B_{t f^{\prime} f p}\right)\right. \\
& \left.* T P R I C E_{f^{\prime} p} * D U T Y_{n p}\right) \\
& -\sum_{v \in V, f \in F, p \in P}\left(R_{t v f p}\right. \\
& \text { *(PPRICE } \left.\left.E_{v p}+P T_{p} * \operatorname{TCOST}_{v f}\right)\right) \\
& -\sum_{v \in V, f \in F, p \in P}\left(\left(R_{t v f p}-R B_{t v f p}\right)\right. \\
& \text { *PPRICE } \left.{ }_{v p} * \operatorname{DUTY}_{n p}\right) \\
& -\sum_{f \in F, p \in P}\left(M_{t f p} * \operatorname{MCOST}_{f p}\right) \\
& -\sum_{f \in F, p \in P}\left(I_{t f p} * \mathrm{PI}_{p} * \operatorname{ICOST}_{f}\right) \\
& \left.-\sum_{f \in F, p \in P}\left(\operatorname{FCOST}_{f}\right)\right) \text { for } t \in T, n \in N
\end{aligned}
$$

where all decision variables (i.e., $R_{t v f p}, M_{t f p}$, etc.) belong to integers.

The objective is to maximize the profits (i.e., expression (1)) in the global SCM model. The revenue of sales (or losses) are obtained from the following statements.
Income Statement

(2): sales of part $p$ in warehouse $w$ minus transportation costs from warehouse $w$ to retailer $r$,

(7): transfer price of part $p$ from facility $f$ to warehouses $w$ (i.e., transfer price),

(8): transfer price of part $p$ from facility $f$ to facility $f^{\prime}$ (i.e., transfer price),

\section{Cost Statement}

(3): transportation and ordering costs from facility $f$ to warehouse $w$,

(4): import duty of part $p$ from facility $f$ to warehouse $w$,

(5): inventory costs of part $p$ in warehouse $w$,

(6): fixed cost in warehouse $w$,

(9): transportation and ordering costs from facility $f$ to warehouse $w$,

(10): import duty of part $p$ from facility $f$ to facility $f^{\prime}$,

(11): transportation and ordering costs from vendor $v$ to facility $f$,

(12): import duty of parts from vendor $v$ to facility,

(13): production cost in facility $f$,

(14): inventory cost in warehouse $w$,

(15): fixed costs in facilities.

Continuously, there are two kinds of constraints in the proposed model. One is flow conservation and the other is upper-lower bound constraints, which are described below.

Flow Conservation

We have

$$
\begin{aligned}
I_{t f p} & +\sum_{v \in V} R_{\left(t-T_{v f}\right) v f p} \\
& +\sum_{f^{\prime} \in F, f^{\prime} \neq f} R_{\left(t-T_{f^{\prime} f}\right) f^{\prime} f p}+M_{\left(t-T b o m_{f p}\right) f p} \\
& -\sum_{p^{\prime} \in P, p \neq p^{\prime}} B O M_{p^{\prime} p} * M_{t f p^{\prime}}-\sum_{f^{\prime} \in F, f^{\prime} \neq f} R_{t f f^{\prime} p} \\
& -\sum_{w \in W} R_{t f w p}=I_{(t+1) f p} \quad \forall t \in T, f \in F, p \in P,
\end{aligned}
$$




$$
\begin{gathered}
I_{t w p}+\sum_{f \in F} R_{\left(t-T_{f w}\right) f w p}-\sum_{r \in R} R_{t w r p}=I_{(t+1) w p} \\
\forall t \in T, w \in W, p \in P, \\
I B_{t f p}+\sum_{v \in V} R B_{\left(t-T_{v f}\right) v f p}+\sum_{f^{\prime} \in F, f^{\prime} \neq f} R B_{\left(t-T_{f^{\prime} f}\right) f^{\prime} f p} \\
+M B_{\left(t-T b o m_{f p}\right) f p}-\sum_{p^{\prime} \in P, p^{\prime} \neq p} B O M_{p^{\prime} p} * M B_{t f p^{\prime}} \\
-\sum_{f^{\prime}} R B_{t f f^{\prime} p}-\sum_{w} R B_{t f w p}=I B_{(t+1) f p} \\
\forall t \in T, f \in F, p \in P, \\
I B_{t w p}+\sum_{f \in F} R B_{\left(t-T_{f w}\right) f w p}-\sum_{r \in R} R_{t w r p}=I B_{(t+1) w p} \\
\forall t \in T, w \in W, p \in P, \\
\sum_{w \in W} R_{\left(t-T_{w r}\right) w r p}=D_{t r p} \quad \forall t \in T, r \in R, p \in P .
\end{gathered}
$$

These flow conservation constraints are described as follows:

(16): the limitation of the flow conservation in each facility,

(17): the limitation of the flow conservation in each warehouse,

(18): the limited bonded parts of the flow conservation in each facility,

(19): the limited bonded parts of the flow conservation in each warehouse,

(20): all of the supplied goods satisfy with retailer demand.

\section{Upper-Lower Bound}

We have

$$
\begin{aligned}
M_{t f p} & \leq M_{-} U_{f p}, \\
I_{t f p} & \leq I_{-} U_{f p}, \\
I_{t w p} & \leq I_{-} U_{w p}, \\
R_{t v f p} & \leq R_{-} U_{v f p}, \\
R_{t f f^{\prime} p} & \leq R_{-} U_{f f^{\prime} p}, \\
R_{t f w p} & \leq R_{-} U_{f w p}, \\
R_{t w r p} & \leq R \_U_{w r p}, \\
R B_{t v f p} & \leq R_{t v f p}, \\
R B_{t f f^{\prime} p} & \leq R_{t f f^{\prime} p}, \\
R B_{t f w p} & \leq R_{t f w p},
\end{aligned}
$$

for $t \in T, v \in V, f, f^{\prime} \in F$ and $f \neq f^{\prime}, p \in P, w \in W$, and $r \in R$.
TABle 1: Profit ratio.

\begin{tabular}{lcc}
\hline Items & Objective & Profit ratio \\
\hline $\begin{array}{l}\text { Having bonded } \\
\text { warehouse }(\mathrm{Hb})\end{array}$ & $\$ 603,010$ & $14.6 \% \uparrow((\mathrm{Hb}-\mathrm{Wb}) / \mathrm{Hb})$ \\
$\begin{array}{l}\text { Without bonded } \\
\text { warehouse }(\mathrm{Wb})\end{array}$ & $\$ 514,680$ & \\
\hline
\end{tabular}

TABLE 2: Vendor location.

\begin{tabular}{lccc}
\hline$L O C_{v}$ & $v_{1}$ & $v_{2}$ & $v_{3}$ \\
\hline Location & 1 (Taiwan) & 2 (China) & 3 (Japan) \\
\hline
\end{tabular}

TABLE 3: Facility location.

\begin{tabular}{lcccc}
\hline LOC $_{f}$ & $f_{1}$ & $f_{2}$ & $f_{3}$ & $f_{4}$ \\
\hline Location & 1(Taiwan) & 2 (China) & 2 (China) & 3(Japan) \\
\hline
\end{tabular}

TABLE 4: Warehouse location.

\begin{tabular}{lcccc}
\hline LOC $_{w}$ & $w_{1}$ & $w_{2}$ & $w_{3}$ & $w_{4}$ \\
\hline Location & 1 (Taiwan) & 2 (China) & 2 (China) & 3 (Japan) \\
\hline
\end{tabular}

TABLE 5: Retailer location.

\begin{tabular}{lccc}
\hline LOC $_{r}$ & $r_{1}$ & $r_{2}$ & $r_{3}$ \\
\hline Location & 1 (Taiwan) & 2 (China) & 3 (Japan) \\
\hline
\end{tabular}

TABLE 6: The weighting of transportation costs of parts.

\begin{tabular}{lccccc}
\hline$P T_{p}$ & $p_{1}$ & $p_{2}$ & $p_{3}$ & $p_{4}$ & $p_{5}$ \\
\hline Weighting & 1 & 0.2 & 0.8 & 0.1 & 0.5 \\
\hline
\end{tabular}

The upper-lower bound constraints are noted as follows:

(21): capacities in which facilities produce goods,

(22): inventory of parts in facilities,

(23): inventory of parts in warehouses,

(24): quantities of raw parts transported from vendors to facilities,

(25): quantities of parts transported from facilities to facilities,

(26): quantities of parts transported from facilities to warehouses,

(27): quantities of parts transported from the warehouse to retailers,

(28): quantities of bonded parts transported from vendors to facilities,

(29): quantities of bonded parts transported from facilities to other facilities,

(30): quantities of bonded parts transported from facilities to warehouses. 
TABLE 7: The weighting of inventory costs of parts.

\begin{tabular}{llllll}
\hline$P I_{p}$ & $p_{1}$ & $p_{2}$ & $p_{3}$ & $p_{4}$ & $p_{5}$ \\
\hline Weighting & 0.5 & 0.1 & 0.5 & 0.1 & 0.4 \\
\hline
\end{tabular}

TABLE 8: The duty of parts in different nations.

\begin{tabular}{|c|c|c|c|c|c|}
\hline$\overline{D U T Y_{n p}}$ & $p_{1}$ & $p_{2}$ & $p_{3}$ & $p_{4}$ & $p_{5}$ \\
\hline$n_{1}$ & 0.2 & 0.3 & 0.2 & 0.01 & 0.05 \\
\hline$n_{2}$ & 0.3 & 0.02 & 0.3 & 0.01 & 0.1 \\
\hline$n_{3}$ & 0.1 & 0.01 & 0.1 & 0.05 & 0.03 \\
\hline
\end{tabular}

TABLE 9: The tax in different nations.

\begin{tabular}{lcc}
\hline & $\operatorname{Tax}_{n}$ & \\
$n_{1}$ & $n_{2}$ & $n_{3}$ \\
\hline 0.07 & 0.03 & 0.08 \\
\hline
\end{tabular}

TABLE 10: Sales price of each part for each vendor.

\begin{tabular}{|c|c|c|c|c|c|}
\hline${ }_{P P R I C E_{v p}}$ & $p_{1}$ & $p_{2}$ & $p_{3}$ & $p_{4}$ & $p_{5}$ \\
\hline$v_{1}$ & & & & 28 & \\
\hline$v_{2}$ & & & & & 40 \\
\hline$v_{3}$ & & 40 & & 30 & \\
\hline
\end{tabular}

All blank cells are disabled.

TABLE 11: Maximum supplied limitation in each vendor.

\begin{tabular}{lcccc}
\hline$R \_U_{v f p}$ & $f_{1}$ & $f_{2}$ & $f_{3}$ & $f_{4}$ \\
\hline$v_{1}$ & 0 & $p_{4}=1000$ & 0 & 0 \\
$v_{2}$ & 0 & 0 & $p_{5}=500$ & $p_{5}=500$ \\
$v_{3}$ & $p_{2}=750, p_{4}=1500$ & 0 & $p_{3}=1500$ & $p_{2}=700$ \\
\hline
\end{tabular}

All blank cells are disabled.

TAble 12: Production costs and limitations for each facility.

\begin{tabular}{|c|c|c|c|c|c|}
\hline $\operatorname{MCOST}_{f p} / M_{-} U_{f p}$ & $p_{1}$ & $p_{2}$ & $p_{3}$ & $p_{4}$ & $p_{5}$ \\
\hline$\overline{f_{1}}$ & $20 / 400$ & & & & \\
\hline$f_{2}$ & & & $30 / 350$ & & \\
\hline$f_{3}$ & & & $28 / 300$ & & \\
\hline$f_{4}$ & $30 / 450$ & & & & \\
\hline
\end{tabular}

All blank cells are disabled.

TABLE 13: Transportation costs and lead time from each vendor to each facility.

\begin{tabular}{lcccc}
\hline $\operatorname{TCOST}_{v f} / T_{v f}$ & $f_{1}$ & $f_{2}$ & $f_{3}$ & $f_{4}$ \\
\hline$v_{1}$ & & $3 / 1$ & & \\
$v_{2}$ & & $1 / 1$ & $1 / 1$ & \\
$v_{3}$ & $4 / 2$ & & $3 / 1$ & $2 / 1$ \\
\hline
\end{tabular}

\section{A Procedure of Global SCM}

There are different procedures in a global supply chain environment such as optimal transportation in logistic management, demand forecasting in preprocessing, bill of materials' $(B O M)$ table, and considering the liberalization policies with bonded warehouses. These procedures are discussed below.
TABLE 14: Amount of part $p$ needed for producing part $p^{\prime}$.

\begin{tabular}{lccccc}
\hline BOM & $p_{1}^{\prime}$ & $p_{2}^{\prime}$ & $p_{3}^{\prime}$ & $p_{4}^{\prime}$ & $p_{5}^{\prime}$ \\
\hline$p_{1}$ & 0 & 2 & 1 & 0 & 0 \\
$p_{2}$ & 0 & 0 & 0 & 0 & 0 \\
$p_{3}$ & 0 & 0 & 0 & 1 & 1 \\
$p_{4}$ & 0 & 0 & 0 & 0 & 0 \\
$p_{5}$ & 0 & 0 & 0 & 0 & 0 \\
\hline
\end{tabular}

TABLE 15: The lead time of the facility for producing part $p^{\prime}$ and sales price in the facility.

\begin{tabular}{|c|c|c|c|c|c|}
\hline Tbom $_{f p} /$ TPRICE $E_{f p}$ & $p_{1}$ & $p_{2}$ & $p_{3}$ & $p_{4}$ & $p_{5}$ \\
\hline$f_{1}$ & $1 / 250$ & & & & \\
\hline$f_{2}$ & & & $1 / 150$ & & \\
\hline$f_{3}$ & & & $1 / 150$ & & \\
\hline$f_{4}$ & $1 / 260$ & & & & \\
\hline
\end{tabular}

TABLE 16: The base of inventory costs.

\begin{tabular}{lcccc}
\hline & & ICOST $_{f}$ & & \\
$f_{1}$ & $f_{2}$ & & $f_{3}$ & $f_{4}$ \\
\hline 6 & 2 & & 1 & 12 \\
\hline
\end{tabular}

TABLE 17: Maximum stock level in each facility.

\begin{tabular}{lccccc}
\hline$I_{-} U_{f p}$ & $p_{1}$ & $p_{2}$ & $p_{3}$ & $p_{4}$ & $p_{5}$ \\
\hline$f_{1}$ & 200 & 400 & 200 & 0 & 0 \\
$f_{2}$ & 0 & 0 & 300 & 300 & 300 \\
$f_{3}$ & 0 & 0 & 400 & 400 & 400 \\
$f_{4}$ & 100 & 200 & 100 & 0 & 0 \\
\hline
\end{tabular}

TABLE 18: Transportation costs and lead time from one facility to another facility.

\begin{tabular}{lcccc}
\hline$T \operatorname{TCOST} T_{f f^{\prime}} / T_{f f^{\prime}}$ & $f_{1}$ & $f_{2}$ & $f_{3}$ & $f_{4}$ \\
\hline$f_{1}$ & & & & \\
$f_{2}$ & $2 / 2$ & & & $3 / 2$ \\
$f_{3}$ & & & & \\
$f_{4}$ & & & & \\
\hline All blank cells are disabled. & & &
\end{tabular}

TABLE 19: Maximum transferable quantity from one facility to another facility.

\begin{tabular}{lcccc}
\hline$R_{-} U_{f f^{\prime} p}$ & $f_{1}$ & $f_{2}$ & $f_{3}$ & $f_{4}$ \\
\hline$f_{1}$ & 0 & 0 & 0 & 0 \\
$f_{2}$ & $p_{3}=1000$ & 0 & 0 & 0 \\
$f_{3}$ & 0 & 0 & 0 & $p_{3}=1000$ \\
$f_{4}$ & 0 & 0 & 0 & 0 \\
\hline
\end{tabular}

3.1. Logistic Management. In this study, we assume that a global SCM goes through four stages such as procurement, production, warehousing, and distribution (i.e., $T_{v f}+$ 
TABLE 20: The base of inventory costs and fixed costs.

\begin{tabular}{lccc}
\hline \multicolumn{4}{c}{$\operatorname{ICOST}_{w}\left(\right.$ FCOST $\left._{w}\right)$} \\
$w_{1}$ & $w_{2}$ & $w_{3}$ & $w_{4}$ \\
\hline $5(50)$ & $1(10)$ & $1(10)$ & $10(100)$ \\
\hline
\end{tabular}

TABLE 21: Transportation costs and lead time from the facility to the warehouse.

\begin{tabular}{llccc}
\hline $\operatorname{TCOST}_{f w} / T_{f w}$ & $w_{1}$ & $w_{2}$ & $w_{3}$ & $w_{4}$ \\
\hline$f_{1}$ & $1 / 1$ & & & \\
$f_{2}$ & $2 / 1$ & 1 & & \\
$f_{3}$ & & & $1 / 1$ & \\
$f_{4}$ & & & & $1 / 1$ \\
\hline
\end{tabular}

All blank cells are disabled.

TABLE 22: Maximum transferable quantity from the facility to the warehouse.

\begin{tabular}{lcccc}
\hline$R \_U_{f w p}$ & $w_{1}$ & $w_{2}$ & $w_{3}$ & $w_{4}$ \\
\hline$f_{1}$ & $p_{1}=800$ & 0 & 0 & 0 \\
$f_{2}$ & $p_{3}=800$ & $p_{3}=600$ & 0 & 0 \\
$f_{3}$ & 0 & 0 & $p_{3}=1000$ & 0 \\
$f_{4}$ & $p_{1}=700$ & 0 & 0 & 0 \\
\hline
\end{tabular}

TABLE 23: Transportation costs and lead time from the warehouse to the retailer.

\begin{tabular}{lccc}
\hline $\operatorname{TCOST}_{w r}\left(T_{w r}\right)$ & $r_{1}$ & $r_{2}$ & $r_{3}$ \\
\hline$w_{1}$ & $1(1)$ & & $3(1)$ \\
$w_{2}$ & $2(2)$ & $1(1)$ & \\
$w_{3}$ & & $1(1)$ & \\
$w_{4}$ & & & $1(1)$ \\
\hline
\end{tabular}

All blank cells are disabled.

TABLE 24: Maximum transferable quantity from the warehouse to the retailer.

\begin{tabular}{lccc}
\hline$R_{-} U_{\text {wrp }}$ & $r_{1}$ & $r_{2}$ & $r_{3}$ \\
\hline$w_{1}$ & $p_{1}=700, p_{3}=800$ & 0 & $p_{1}=300$ \\
$w_{2}$ & $p_{3}=800$ & $p_{3}=8000$ & 0 \\
$w_{3}$ & 0 & $p_{3}=800$ & 0 \\
$w_{4}$ & 0 & 0 & $p_{1}=1000$ \\
\hline
\end{tabular}

TABLE 25: Sales price of each part and limitation in each warehouse.

\begin{tabular}{lccccc}
\hline PRICE $_{w p} / I_{-} U_{w p}$ & $p_{1}$ & $p_{2}$ & $p_{3}$ & $p_{4}$ & $p_{5}$ \\
\hline$w_{1}$ & $380 / 300$ & 0 & $280 / 300$ & 0 & 0 \\
$w_{2}$ & 0 & 0 & $200 / 500$ & 0 & 0 \\
$w_{3}$ & 0 & 0 & $200 / 600$ & 0 & 0 \\
$w_{4}$ & $450 / 150$ & 0 & 0 & 0 & 0 \\
\hline
\end{tabular}

$\left.T_{f \_ \text {Bom }}+\left[T_{f f^{\prime}}+T_{f \_ \text {Bom }}\right]+T_{f w}+T_{w r}\right)$, where the semifinished goods will be transferred to another facility for reproduction (i.e., $\left[T_{f f^{\prime}}+T_{f^{\prime} \text { Bom }}\right]$ ) to enhance the transfer price of goods. The course of the logistic management needs to go through a phase or a cycle (i.e., $t=1,2, \ldots, n)$. The processing flow of global SCM is presented in Figure 3.
In order to avoid delaying the demand of retailers in the future, in the beginning, we let the quantities of inventories equal zero in each stage in the first phase. Then, we will add $m$ times for utilizing demand forecast method. The period of $n+m$ times will be calculated in this global. Occurring in the period from $(n+1)$ to $(n+m)$ times, all of the goods in transportation and processing will be restored to the inventories of the adjacent warehouses.

3.2. Demand Forecast Method-Time Series Analysis. As mentioned above, we need to forecast the quantity of retailers' (i.e., customer) demand. Time series forecasting is a wellknown method $[31,32]$ to forecast future demands based on known past events.

By referring to Li's method [33], we then have the following nonlinear time series analysis' model.

A Nonlinear Demand Forecasting Model (NDF Model)

$$
\begin{array}{ll}
\operatorname{Min} & \sum_{t=1}^{T}\left|S_{t}-\left(a+b Q_{t}\right) y_{t}\right| \\
\text { s.t. } & y_{t}=y_{t^{\prime}} \quad\left(\forall t, t^{\prime} \text { and } t \neq t^{\prime}\right. \text {, which mean }
\end{array}
$$

$t$ and $t^{\prime}$ belong to the same quarter),

$$
\sum_{t=1}^{k} y_{t}=k
$$

$y_{t} \geq 0, \quad S_{t}, a$, and $b$ are free sign variables,

where $k$ is sum of seasons (usually $k=4$ ) and $S_{t}, Q_{t}$, and $y_{t}$ denotes the sales, quarter numbers, and seasonal indexes, respectively. For example, if $T=8$, then $t=(1,5)$ represent the first quarter, $t=(2,6)$ represent the second quarter, $t=$ $(3,7)$ represent the third quarter, and $t=(4,8)$ represent the fourth quarter.

A NDF model is nonlinear because of existing absolute functions and nonlinear terms. Following linear systems can linearize them. The linear approximation of the function $F_{1, t}\left(a, y_{t}\right)=a y_{t}$ is a continuous function $f_{1, t}\left(a, y_{t}\right)$, which is equal to $F_{1, t}\left(a, y_{t}\right)$ (i.e., $f_{1, t}\left(a_{l_{1}}, a_{t, l_{2}}\right)=F_{1, t}\left(a, y_{t}\right)$ at each grid point $\left.\left(l_{1}, l_{2}\right)\right)$ and a linear function of its variables $\left(a, y_{t}\right)$ on the interior or edges of each of the indicated triangles. To describe the linear approximation of the function $F_{1, t}\left(a, y_{t}\right)$, we then have the following linear system (referring to the models in Babayev [34]).

Let

$$
\begin{aligned}
f_{1, t}\left(a, y_{t}\right) & =a y_{t} \cong \alpha_{t} \\
& =\sum_{l_{1}=1}^{m+1} \sum_{l_{2}=1}^{m+1} F_{1, i}\left(d_{1, l_{1}}, d_{2, t, l_{2}}\right) \omega_{l_{1}, l_{2}}, \\
a & =\sum_{l_{1}=1}^{m+1} \sum_{l_{2}=1}^{m+1} d_{1, l_{1}} \omega_{l_{1}, l_{2}},
\end{aligned}
$$


TABLE 26: Retailer demand and forecasting at each time.

\begin{tabular}{|c|c|c|c|c|c|c|c|c|c|c|c|c|c|c|c|}
\hline \multirow[b]{2}{*}{$D_{\operatorname{trp}}$} & \multicolumn{5}{|c|}{ Retailer $R_{1}$} & \multicolumn{5}{|c|}{ Retailer $R_{2}$} & \multicolumn{5}{|c|}{ Retailer $R_{3}$} \\
\hline & $p_{1}$ & $p_{2}$ & $p_{3}$ & $p_{4}$ & $p_{5}$ & $p_{1}$ & $p_{2}$ & $p_{3}$ & $p_{4}$ & $p_{5}$ & $p_{1}$ & $p_{2}$ & $p_{3}$ & $p_{4}$ & $p_{5}$ \\
\hline$t=1$ & 0 & 0 & 0 & 0 & 0 & 0 & 0 & 0 & 0 & 0 & 0 & 0 & 0 & 0 & 0 \\
\hline$t=2$ & 0 & 0 & 0 & 0 & 0 & 0 & 0 & 0 & 0 & 0 & 0 & 0 & 0 & 0 & 0 \\
\hline$t=3$ & 0 & 0 & 0 & 0 & 0 & 0 & 0 & 0 & 0 & 0 & 0 & 0 & 0 & 0 & 0 \\
\hline$t=4$ & 0 & 0 & 0 & 0 & 0 & 0 & 0 & 0 & 0 & 0 & 0 & 0 & 0 & 0 & 0 \\
\hline$t=5$ & 0 & 0 & 0 & 0 & 0 & 0 & 0 & 0 & 0 & 0 & 0 & 0 & 0 & 0 & 0 \\
\hline$t=6$ & 0 & 0 & 180 & 0 & 0 & 0 & 0 & 120 & 0 & 0 & 0 & 0 & 0 & 0 & 0 \\
\hline$t=7$ & 0 & 0 & 190 & 0 & 0 & 0 & 0 & 110 & 0 & 0 & 0 & 0 & 0 & 0 & 0 \\
\hline$t=8$ & 52 & 0 & 170 & 0 & 0 & 0 & 0 & 100 & 0 & 0 & 83 & 0 & 0 & 0 & 0 \\
\hline$t=9$ & 38 & 0 & 160 & 0 & 0 & 0 & 0 & 130 & 0 & 0 & 90 & 0 & 0 & 0 & 0 \\
\hline$t=10$ & 60 & 0 & 210 & 0 & 0 & 0 & 0 & 120 & 0 & 0 & 50 & 0 & 0 & 0 & 0 \\
\hline$t=11$ & 43 & 0 & 180 & 0 & 0 & 0 & 0 & 110 & 0 & 0 & 60 & 0 & 0 & 0 & 0 \\
\hline$t=12$ & 52 & 0 & 190 & 0 & 0 & 0 & 0 & 100 & 0 & 0 & 76 & 0 & 0 & 0 & 0 \\
\hline$t=13$ & 56 & 0 & 170 & 0 & 0 & 0 & 0 & 110 & 0 & 0 & 56 & 0 & 0 & 0 & 0 \\
\hline$t=14$ & 48 & 0 & 180 & 0 & 0 & 0 & 0 & 130 & 0 & 0 & 76 & 0 & 0 & 0 & 0 \\
\hline$t=15$ & 58 & 0 & 200 & 0 & 0 & 0 & 0 & 120 & 0 & 0 & 99 & 0 & 0 & 0 & 0 \\
\hline$t=16$ & 31 & 0 & 190 & 0 & 0 & 0 & 0 & 90 & 0 & 0 & 80 & 0 & 0 & 0 & 0 \\
\hline$t=17$ & 52 & 0 & 180 & 0 & 0 & 0 & 0 & 120 & 0 & 0 & 50 & 0 & 0 & 0 & 0 \\
\hline
\end{tabular}

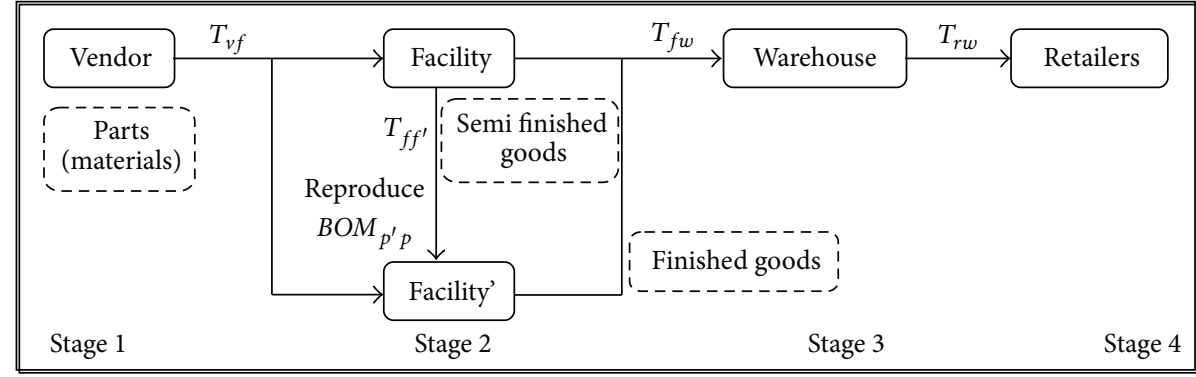

FIgURE 3: Processing flow of the global SCM.

$$
\begin{aligned}
& y_{t}=\sum_{l_{1}=1}^{m+1} \sum_{l_{2}=1}^{m+1} d_{2, t, l_{2}} \omega_{l_{1}, l_{2}} \\
& \sum_{l_{1}=1}^{m+1} \sum_{l_{2}=1}^{m+1} \omega_{l_{1}, l_{2}}=1 \text {, } \\
& \sum_{l_{1}=1}^{m} \sum_{l_{2}=1}^{m}\left(u_{l_{1}, l_{2}}+v_{l_{1}, l_{2}}\right)=1 \text {, } \\
& \omega_{l_{1}, l_{2}}+\omega_{l_{1}, l_{2}+1}+\omega_{l_{1}+1, l_{2}+1} \geq u_{l_{1}, l_{2}} \text { for } l_{1}=1, \ldots, m \text {, } \\
& l_{2}=1, \ldots, m, \\
& \omega_{l_{1}, l_{2}}+\omega_{l_{1}+1, l_{2}}+\omega_{l_{1}+1, l_{2}+1} \geq v_{l_{1}, l_{2}} \quad \text { for } l_{1}=1, \ldots, m \text {, } \\
& l_{2}=1, \ldots, m
\end{aligned}
$$

where $\omega_{l_{1}, l_{2}} \geq 0$ and $u_{l_{1}, l_{2}}, v_{l_{1}, l_{2}} \in\{0,1\}$.

Expressions (36) (38) define the point $\left(a, y_{t}\right)$ as the convex linear combination of the vertices of the chosen triangle.
Expressions (39) (41) imply that if $u_{l_{1}, l_{2}}=1$, then $\omega_{l_{1}, l_{2}}+$ $\omega_{l_{1}, l_{2}+1}+\omega_{l_{1}+1, l_{2}+1}=1$ and $f_{1, t}\left(a, y_{t}\right)=\stackrel{F}{F}, t_{1, l_{1}}\left(d_{1, t, l_{2}}\right) \omega_{l_{1}, l_{2}}+$ $F_{1, t}\left(d_{1, l_{1}}, d_{2, t, l_{2}+1}\right) \omega_{l_{1}, l_{2}+1}+F_{1, t}\left(d_{1, l_{1}+1}, d_{2, t, l_{2}+1}\right) \omega_{l_{1}+1, l_{2}+1}$; or if $v_{l_{1}, l_{2}}=1$, then $\omega_{l_{1}, l_{2}}+\omega_{l_{1}+1, l_{2}}+\omega_{l_{1}+1, l_{2}+1}=1$ and $f_{1, t}\left(a, y_{t}\right)=F_{1, t}\left(d_{1, l_{1}}, d_{2, t, l_{2}}\right) \omega_{l_{1}, l_{2}}+F_{1, t}\left(d_{1, l_{1}+1}, d_{2, t, l_{2}}\right) \omega_{l_{1}+1, l_{2}}+$ $F_{1, t}\left(d_{1, l_{1}+1}, d_{2, t, l_{2}+1}\right) \omega_{l_{1}+1, l_{2}+1}$.

The mentions above give a basic formulation satisfying the piecewise linear approximation of $F_{1, t}\left(a, y_{t}\right)=a y_{t} \cong \alpha_{t}$. Similarly, $F_{2, t}\left(b, y_{t}\right)=b y_{t} \cong \beta_{t}$ can be also linearized by the same way (for the proof, refer to Babayev [34]).

On the other hand, we use additional binary variables to treat the absolute function. A piecewisely linear demand forecasting model can be reformulated as follows.

A Piecewisely Linear Demand Forecasting Model (PLDF Model)

$$
\begin{array}{ll}
\operatorname{Min} & \sum_{t=1}^{T} \Phi_{t} \\
\text { s.t. } & (32) \text { and (33), }
\end{array}
$$




\begin{tabular}{|c|c|c|c|c|c|}
\hline Parts & $p_{1}$ & $p_{2}$ & $p_{3}$ & $p_{4}$ & $p_{5}$ \\
\hline$p_{1}$ & - & 2 & 1 & - & - \\
\hline$p_{2}$ & - & - & - & - & - \\
\hline$p_{3}$ & - & - & - & 1 & 1 \\
\hline$p_{4}$ & - & - & - & - & 0 \\
\hline$p_{5}$ & - & - & - & - & - \\
\hline
\end{tabular}

Figure 4: $B O M$ figure.

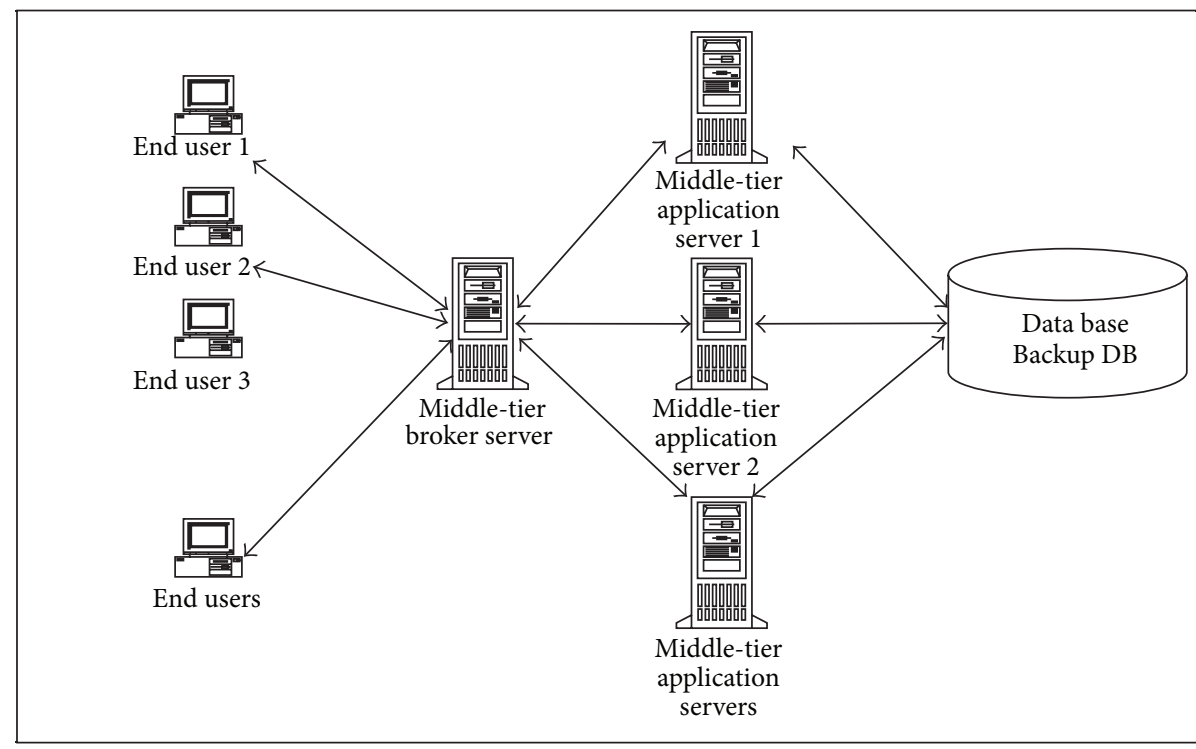

FIgURE 5: Architecture of the multitier web server.

$$
\begin{gathered}
\left(u_{t}-1\right) M+S_{t}-\left(\alpha_{t}+\beta_{t} Q_{t}\right) \\
\quad \leq \Phi_{t} \leq S_{t}-\left(\alpha_{t}+\beta_{t} Q_{t}\right)+\left(1-u_{t}\right) M, \\
-u_{t} M+\left(\alpha_{t}+\beta_{t} Q_{t}\right)-S_{t} \\
\quad \leq \Phi_{t} \leq\left(\alpha_{t}+\beta_{t} Q_{t}\right)-S_{t}+u_{t} M,
\end{gathered}
$$

where $M$ is a big enough constant, $u_{t} \in\{0,1\}, \Phi_{t} \geq 0, \alpha_{t}$, and $\beta_{t}$ are piecewisely linear variables of $a y_{t}$ and $b y_{t}$, respectively, referred to(35)-(41).

Considering the following situations we know that the nonlinear objective function can be linearized by linear system, that is, (44) and (45).

(i) If $u_{t}=1$, then $\Phi_{t}=S_{t}-\left(\alpha_{t}+\beta_{t} Q_{t}\right)$, which is forced by (44) because of $\Phi_{t} \geq 0$,

(ii) If $u_{t}=0$, then $\Phi_{t}=\left(\alpha_{t}+\beta_{t} Q_{t}\right)-S_{t}$, which is forced by (45) because of $\Phi_{t} \geq 0$.

3.3. Bill of Materials (BOM). A bill of materials' (BOM) table is expressed as the "parts list" of components. In order to understand the BOM for this global SCM model, the symbols of $p$ and $p^{\prime}$ could be expressed as a material or goods (i.e., parameter $\left.B O M_{p^{\prime} p}\right)$. Hence, we can utilize a two-dimensional matrix to express the relationship between partial and goods.
For example, a $p_{4}$ with a $p_{5}$ can produce a $p_{3}$, and a $p_{3}$ with two $p_{2}$ can produce a $p_{1}$. The $B O M$ table of the sparse matrix is expressed in Figure 4. The aim is to design a friendly interface for our system design.

3.4. Liberalization Policy with Bonded Warehouses. This study proposes a global SCM model which is capable of treating liberalization policy for bonded warehouses in the different countries around the world [24-28]. A bonded warehouse is one building or any other secured area, where dutiable goods may be stored or processed without payment of duty. It may be managed by the state or by private enterprise.

While the goods are stored in the bonded warehouse, the liability of exporter is temporally cancelled, and the importer and warehouse proprietor incur liability. These goods are in the bonded warehouse, and they may be processed by assembling, sorting, repacking, or others. After processing and within the warehousing period, the goods may be exported without the payment of duty, or they may be withdrawn for consumption upon payment of duty at the rate applicable to the goods in their manipulated condition at the time of withdrawal. Bonded warehouses provide specialized storage services such as deep freeze, bulk liquid storage, commodity 


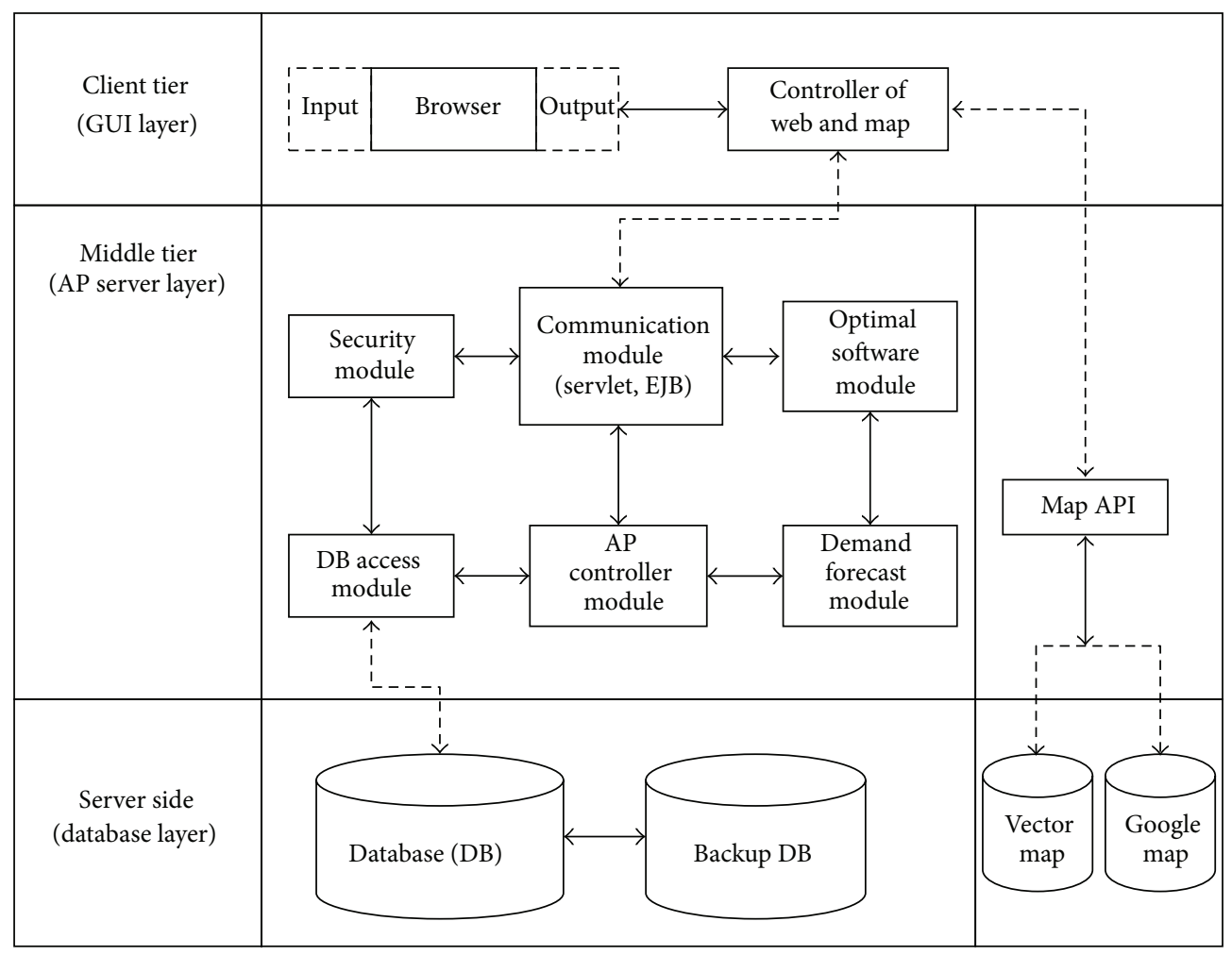

Figure 6: Architecture of the global SCM system.

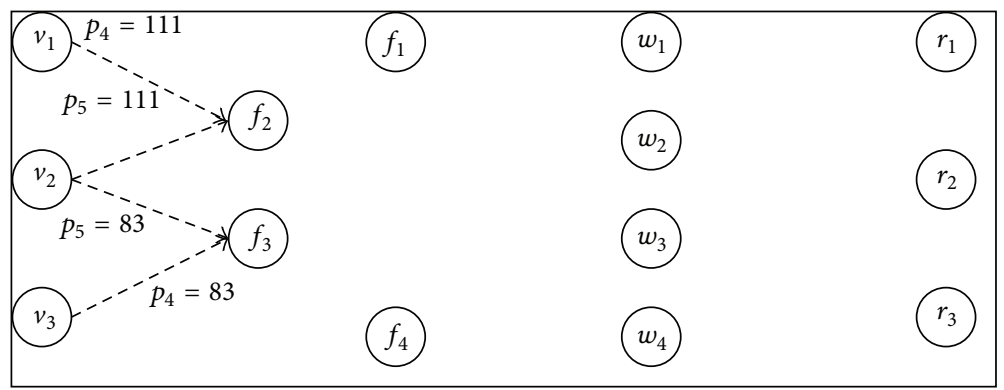

FIgURE 7: The logistic flow at time $=1$.

processing, and coordination with transportation and are an integral part of the global supply chain.

The liberalization policy with bonded warehouses not only enhances the industries competitiveness but also saves inventory, production, and transportation costs. Of course, the objective aims to find more bonded warehouses, and more costs could be saved.

\section{System Development}

Currently, global supply chain management (global SCM) system always needs experts offering the qualities of goods in bonded warehouses to calculate the production capacity since there is a lack of kernel technique (i.e., deterministic mathematical model) for developing global SCM system. At the same time, considering the policy of trade liberalization with bonded warehouses by manual is a difficult job. Therefore, this study develops a global SCM system with optimization technique to cope with the bonded warehouses for obtaining the maximal profits, automatically.

4.1. System Design. This study designs a system to apply for a global SCM system based on a proposed mathematical model. The architecture of the global SCM system includes an application server in the middle tier to distribute all of the processing jobs. Establishing a Broker Server can not only distribute the jobs into different application servers, but also the jobs work much more efficient. The basic architecture of the global SCM system is shown in Figure 5.

Furthermore, the system architecture includes three tiers which are composed of various modules. In the first tier, GUI layer, an intuitive and friendly interface for users is built. In the second tier, the application (AP) server layer, 


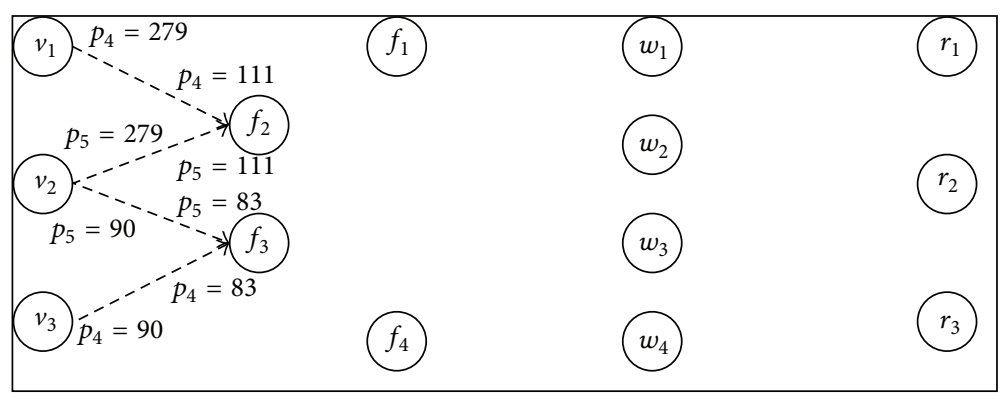

Figure 8: The logistic flow at time $=2$.

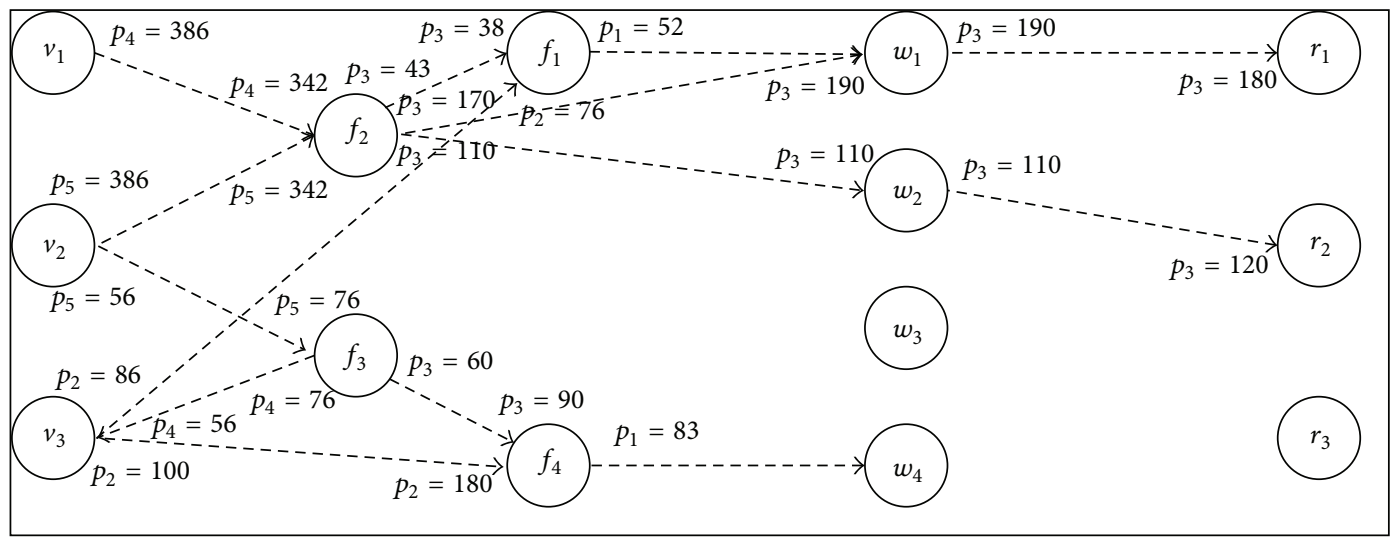

Figure 9: The logistics flow at time $=6$.

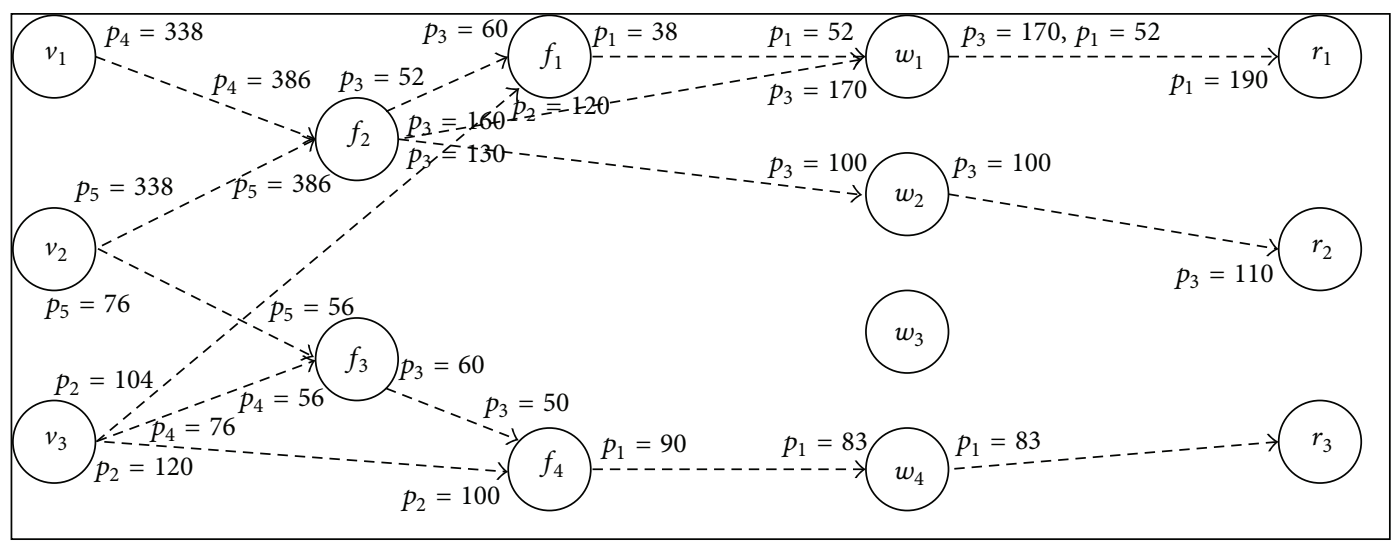

Figure 10: The logistic flow at time $=7$.

is a kernel in the global SCM system whose base is based on the Java programming language and an optimal software component (i.e., LINGO's Solver). In the last tier, database layer stores all of the data such as the username, password, environment setting, and logistics information into database system. Moreover, the data must be backed up to the other database to protect it from hacking or crashing. Then, the system architecture is shown in Figure 6.

\section{Numerical Examples}

In our numerical examples, we assume that the situation occurred in three different overseas locations. There are three vendors $\left(v_{1}, v_{2}, v_{3}\right)$, four facilities $\left(f_{1}, f_{2}, f_{3}, f_{4}\right)$, four warehouses $\left(w_{1}, w_{2}, w_{3}, w_{4}\right)$, three retailers $\left(r_{1}, r_{2}, r_{3}\right)$. Under the liberalization policies, these limited quantities of bonded warehouses are listed in the Appendix. There are three parts $\left(p_{2}, p_{4}, p_{5}\right)$ supplied from the vendor to the facility, and the parts be produced another two parts $\left(p_{1}, p_{3}\right)$ in different facilities. The period of time includes two demands: one is actual customer demand (i.e., $t_{n}=15$ ), and the other is forecasting demand (i.e., $t_{m}=2$ ), so that the total period of time is 17 (i.e., $t=1$ to 17). The other parameters are expressed in Tables 2, 3, 4, 5, 6, 7, 8, 9, 10, 11, 12, 13, 14, 15, 16, 17, 18, 19, $20,21,22,23,24,25$, and 26 of the Appendix. The numerical example was solved via a global SCM system; these logistic 


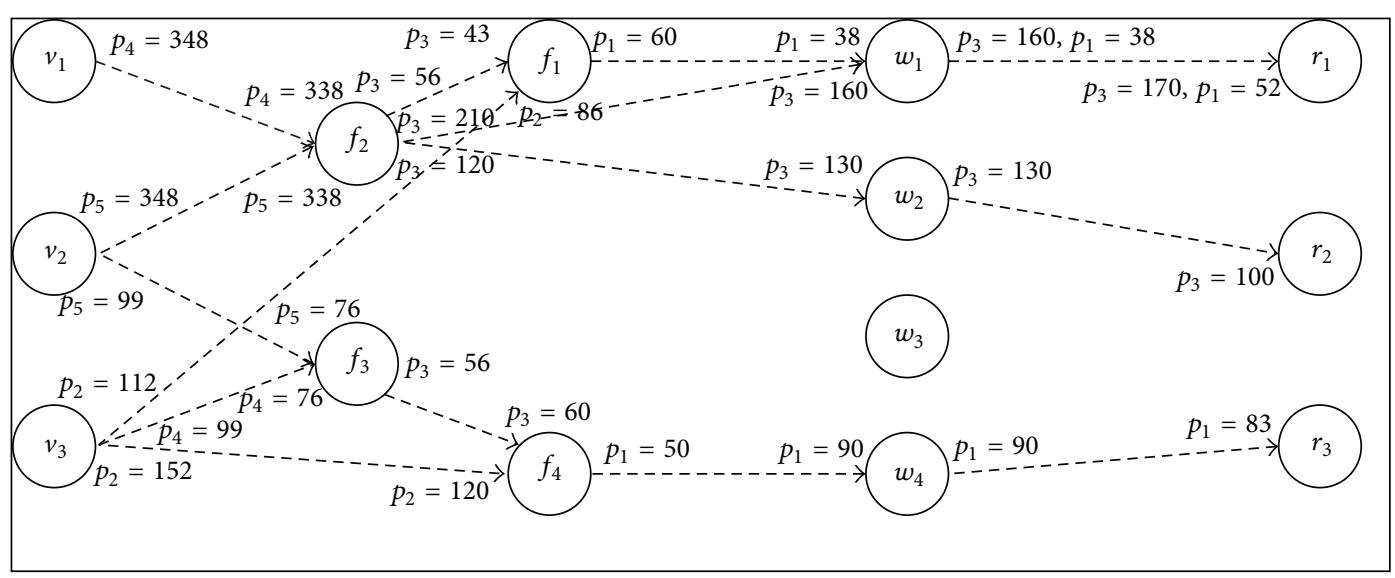

Figure 11: The logistic flow at time $=8$.

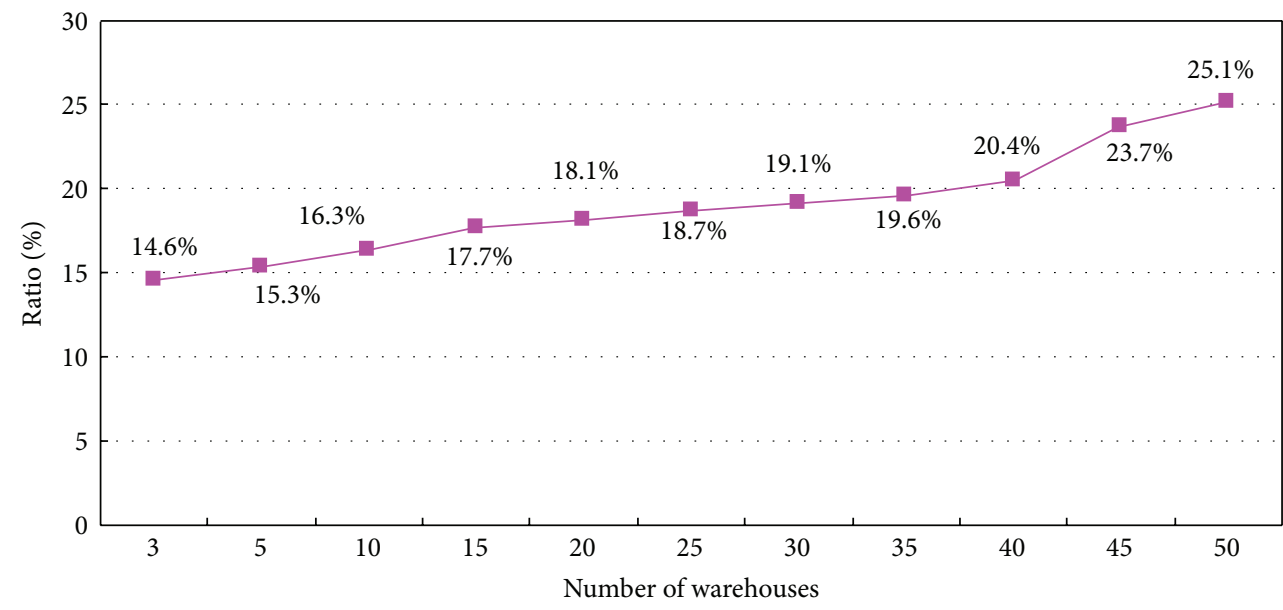

Benefit ratio

FIGURE 12: The tendency of the profit ratios for different numbers of warehouses.

results at different times $t$ are depicted in Figures 7, 8, 9, 10 and 11.

Solving the example, the objective value is $\$ 603,010$ with consideration of the bonded warehouses. We then calculate them without bonded warehouses again, and the objective value is 514,680 . Comparing both of them, the profit ratio increases to $14.6 \%$ as shown in Table 1 .

In order to observe the advantages of the proposed method, this study experiments different numerical examples by generating parameters below.

(i) The total locations are randomly generated from a uniform distribution according to $2 \leq$ vendors $\leq 20$, $3 \leq$ facilities $\leq 20,4 \leq$ warehouses $\leq 20$, and $2 \leq$ retailers $\leq 40$.

(ii) The period of time is randomly generated from the uniform distribution over the range of $[2,16]$.

(iii) The capacities of bonded warehouses are according to the capacities of original warehouses based on uniform distribution from $50 \%$ to $90 \%$. (iv) In order to balance between the supply and demand, all of the coefficients follows feasible sets for the global SCM models.

According to the computational results followed rules (i) to (iv), we observe that the liberalization policy with bonded warehouses directly affects the activities of the global SCMs. When we fixed the number of bonded warehouses to 5 , the profit ratio approaches $15 \%$. When we take the number of bonded warehouses being 40 as an example, the profit ratio enhances to $20 \%$. Finally, the profit ratio is close to $25 \%$ at 50 bonded warehouses. That is, considering that more nodes have bounded constraints, there is a greater cost saving. The tendency of the other 10 tests is depicted in Figure 12.

The proposed model considers the liberalization policy with bonded warehouses as flow-control constraints to obtain optimal profits. Additionally, numerical experiments also illustrate that the proposed model can enhance the profit ratio when the number of bonded warehouses is large. 


\section{Conclusions}

This study proposes a global SCM model which is capable of treating liberalization policy with bonded warehouses. All of the constraints about bonded warehouses can be added to the proposed global SCM model. Additionally, the proposed model is embedded into a global SCM system we developed. The system can automatically calculate the profit ratio to further enhance the competitiveness. Numerical experiments' reports illustrate that the proposed model can be effectively solved to obtain the optimal profit.

Future research can consider different quantity discount policies, artificial neural network method for solving the uncertainty demand forecast, heuristic methods for accelerating solving speed, and linearization technique for resolving the proposed demand forecasting model.

\section{Appendix}

For more details, see Tables 2-26.

\section{Acknowledgments}

The authors would like to thank the editor and anonymous referees for providing most valuable comments for us to improve the quality of this paper. This research was supported by the project granted by ROC NSC 101-2811-E-009-011.

\section{References}

[1] D. J. Thomas and P. M. Griffin, "Coordinated supply chain management," European Journal of Operational Research, vol. 94, no. 1, pp. 1-15, 1996.

[2] S. C. Graves and S. P. Willems, "Optimizing the supply chain configuration for new products," Management Science, vol. 51, no. 8, pp. 1165-1180, 2005.

[3] H. L. Lee and J. Rosenblatt, "A generalized quantity discount pricing model to increase supplier's profits," Management Science, vol. 33, no. 9, pp. 1167-1185, 1986.

[4] J. P. Monahan, "A quantity pricing model to increase vendor profits," Management Science, vol. 30, no. 6, pp. 720-726, 1984.

[5] C. Hofmann, "Supplier's pricing policy in a just-in-time environment," Computers and Operations Research, vol. 27, no. 14, pp. 1357-1373, 2000.

[6] P. C. Yang, "Pricing strategy for deteriorating items using quantity discount when demand is price sensitive," European Journal of Operational Research, vol. 157, no. 2, pp. 389-397, 2004.

[7] J.-F. Tsai, "An optimization approach for supply chain management models with quantity discount policy," European Journal of Operational Research, vol. 177, no. 2, pp. 982-994, 2007.

[8] B. L. Foote, "On the implementation of a control-based forecasting system for aircraft spare parts procurement," IIE Transactions, vol. 27, no. 2, pp. 210-216, 1995.

[9] A. A. Ghobbar and C. H. Friend, "Evaluation of forecasting methods for intermittent parts demand in the field of aviation: a predictive model," Computers and Operations Research, vol. 30, no. 14, pp. 2097-2114, 2003.
[10] F.-L. Chu, "Forecasting tourism demand: a cubic polynomial approach," Tourism Management, vol. 25, no. 2, pp. 209-218, 2004.

[11] X. Zhao, J. Xie, and J. Leung, "The impact of forecasting model selection on the value of information sharing in a supply chain," European Journal of Operational Research, vol. 142, no. 2, pp. 321-344, 2002.

[12] H. L. Lee, V. Padmanabhan, and S. Whang, "The bullwhip effect in supply chains," Sloan Management Review, vol. 38, no. 3, pp. 93-102, 1997.

[13] F. Chen, Z. Drezner, J. K. Ryan, and D. Simchi-Levi, "Quantifying the bullwhip effect in a simple supply chain: the impact of forecasting, lead times, and information," Management Science, vol. 46, no. 3, pp. 436-443, 2000.

[14] R. J. Kuo, "Sales forecasting system based on fuzzy neural network with initial weights generated by genetic algorithm," European Journal of Operational Research, vol. 129, no. 3, pp. 496-517, 2001.

[15] F. B. Gorucu, P. U. Geriş, and F. Gumrah, "Artificial neural network modeling for forecasting gas consumption," Energy Sources, vol. 26, no. 3, pp. 299-307, 2004.

[16] H. C. Chen, H. M. Wee, and Y. H. Hsieh, "Optimal supply chain inventory decision using artificial neural network," in Proceedings of the WRI Global Congress on Intelligent Systems (GCIS '09), pp. 130-134, May 2009.

[17] B. Bilgen, "Application of fuzzy mathematical programming approach to the production allocation and distribution supply chain network problem," Expert Systems with Applications, vol. 37, no. 6, pp. 4488-4495, 2010.

[18] C. R. Moberg, B. D. Cutler, A. Gross, and T. W. Speh, "Identifying antecedents of information exchange within supply chains," International Journal of Physical Distribution and Logistics Management, vol. 32, no. 9, pp. 755-770, 2002.

[19] S. Li and B. Lin, "Accessing information sharing and information quality in supply chain management," Decision Support Systems, vol. 42, no. 3, pp. 1641-1656, 2006.

[20] F.-R. Lin, S.-H. Huang, and S.-C. Lin, "Effects of information sharing on supply chain performance in electronic commerce," IEEE Transactions on Engineering Management, vol. 49, no. 3, pp. 258-268, 2002.

[21] G. P. Cachon and M. Fisher, "Supply chain inventory management and the value of shared information," Management Science, vol. 46, no. 8, pp. 1032-1048, 2000.

[22] C.-C. Huang and S.-H. Lin, "Sharing knowledge in a supply chain using the semantic web," Expert Systems with Applications, vol. 37, no. 4, pp. 3145-3161, 2010.

[23] M.-M. Yu, S.-C. Ting, and M.-C. Chen, "Evaluating the crossefficiency of information sharing in supply chains," Expert Systems with Applications, vol. 37, no. 4, pp. 2891-2897, 2010.

[24] D. Trefler, "Trade liberalization and the theory of endogenous protection: an econometric study of US import policy," Journal of Political Economy, vol. 101, no. 1, pp. 138-160, 1993.

[25] M. S. Iman and A. Nagata, "Liberalization policy over foreign direct investment and the promotion of local firms development in Indonesia," Technology in Society, vol. 27, no. 3, pp. 399-411, 2005.

[26] B. Romagnoli, V. Menna, N. Gruppioni, and C. Bergamini, "Aflatoxins in spices, aromatic herbs, herb-teas and medicinal plants marketed in Italy," Food Control, vol. 18, no. 6, pp. 697701, 2007. 
[27] R. D. C. Israel, "A comparative welfare analysis of the duty drawback and the common bonded warehouse schemes," Philippine Review of Economics, vol. 30, no. 2, 1993.

[28] B. Yang, "Political democratization, economic liberalization, and growth volatility," Journal of Comparative Economics, vol. 39, no. 2, pp. 245-259, 2011.

[29] C.-S. Yu and H.-L. Li, "Robust optimization model for stochastic logistic problems," International Journal of Production Economics, vol. 64, no. 1, pp. 385-397, 2000.

[30] LINGO, Release. 8, Lindo System, Chicago, Ill, USA, 2002.

[31] H. Kantz, T. Schreiber, and R. S. Mackay, Nonlinear Time Series Analysis, Cambridge University Press, Cambridge, UK, 1997.

[32] T. Schreiber, "Interdisciplinary application of nonlinear time series methods," Physics Report, vol. 308, no. 1, pp. 1-64, 1999.

[33] H. L. Li, Supply Chain Management and Decision Making, Nonlinear Models of Supply Chain, chapter 4, 2004.

[34] D. A. Babayev, "Piece-wise linear approximation of functions of two variables," Journal of Heuristics, vol. 2, no. 4, pp. 313-320, 1997. 


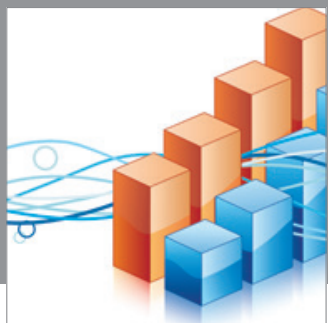

Advances in

Operations Research

mansans

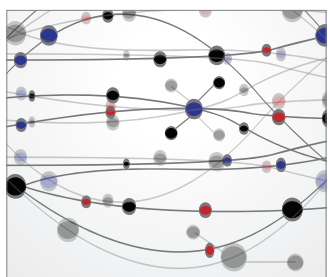

The Scientific World Journal
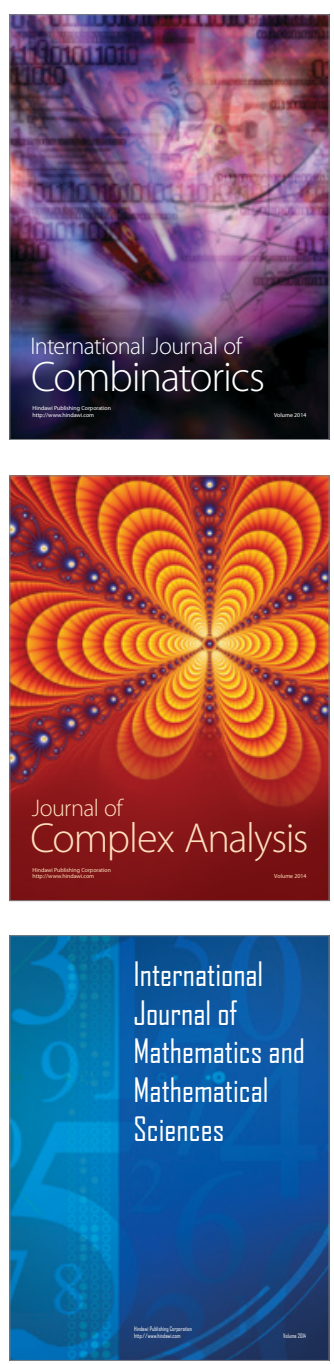
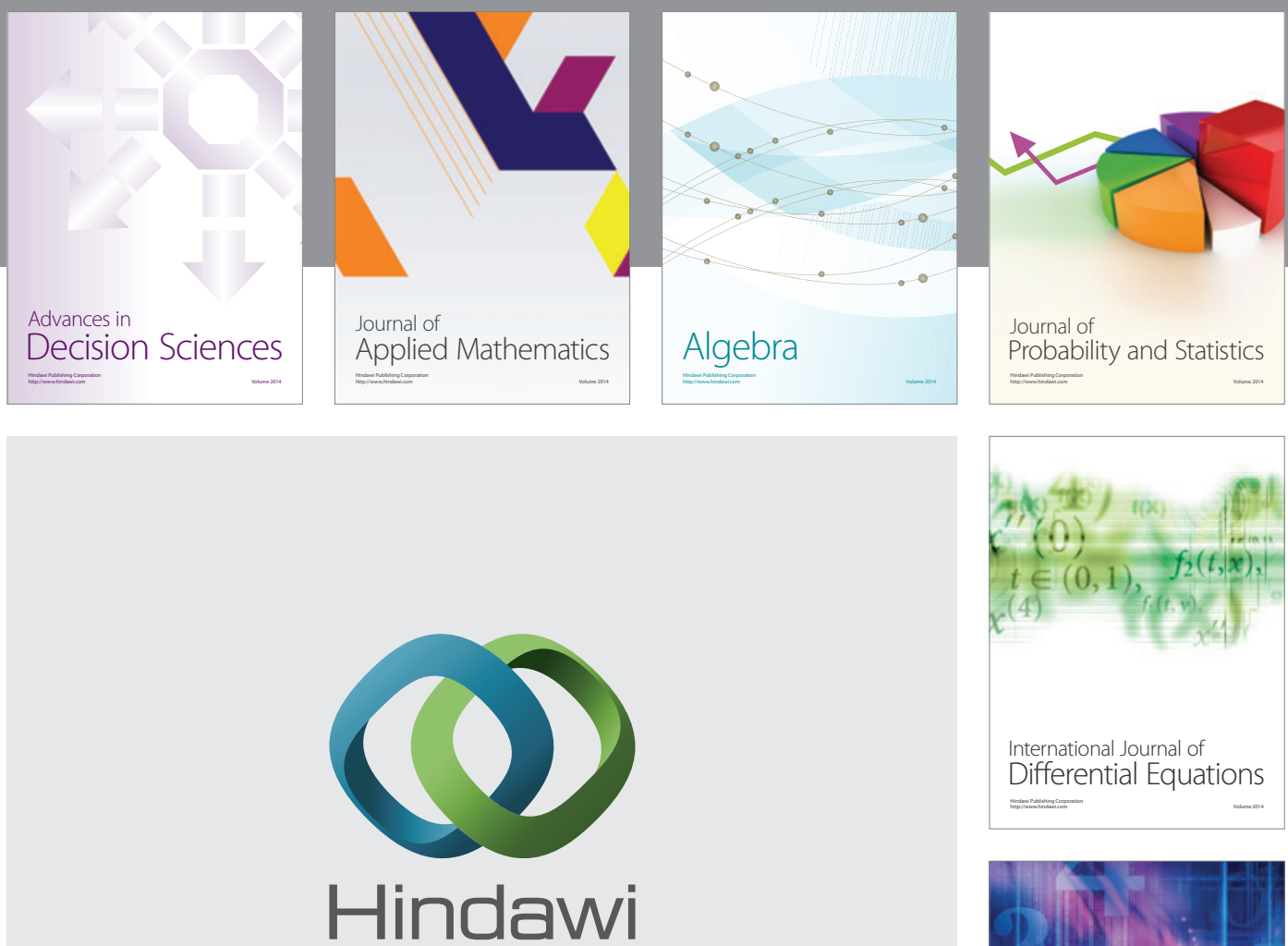

Submit your manuscripts at http://www.hindawi.com
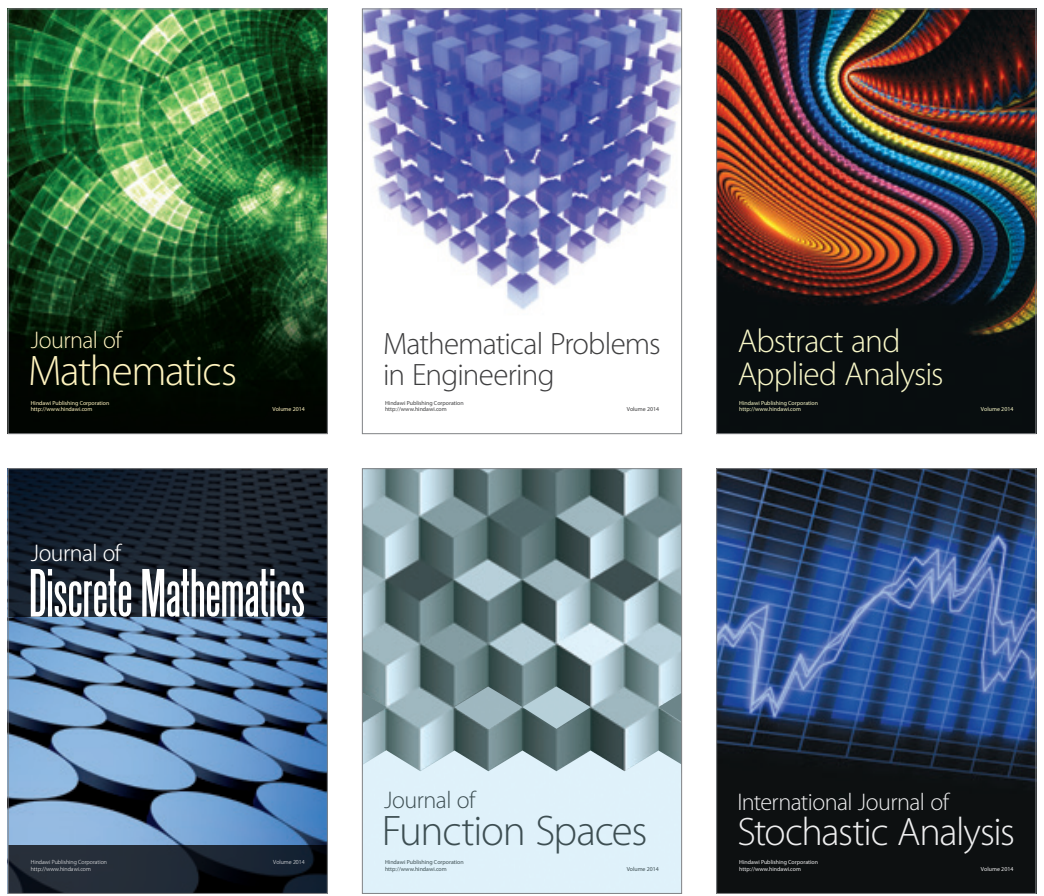

Journal of

Function Spaces

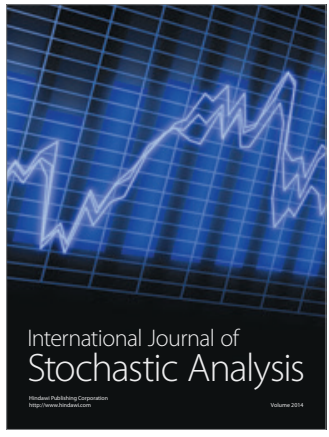

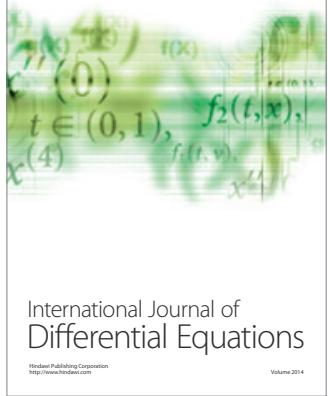
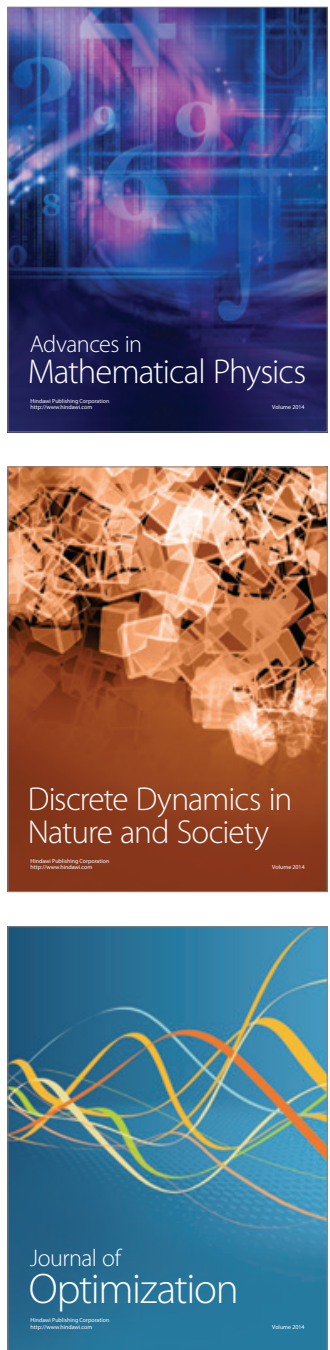